\title{
Improvements in utilizing the scavenge air cooling for enhancing the performance of marine diesel engines
}

\author{
Fady G. Z. Tawadros ${ }^{\# 1}$, Mohamed A.Teamah ${ }^{\# 2}$,Ahmed A. Hanafy ${ }^{\# 3}$,WaelM. EI- \\ Maghlany ${ }^{\# 4}$
}

\#1 Mechanical Engineering Department, College of Engineering and Technology,Arab Academy for Science, Technology and Maritime Transport, Abu-Qir, Alexandria, Egypt, fadygeorgeta@gmail.com

\#2 Mechanical Engineering Department,Faculty of Engineering,Alexandria University, Alexandria, Egypt, mteamah@yahoo.com

\#3 Mechanical Engineering Department, College of Engineering and Technology,Arab Academy for Science, Technology and Maritime Transport, Abu-Qir, Alexandria, Egypt, a_a_hanafy@yahoo.com

\#4Mechanical Engineering Department,Faculty of Engineering,Alexandria University, Alexandria, Egypt, elmaghlany@yahoo.com

\section{ABSTRACT}

The issue of recovering energy lost from large marine diesel engines has been one of the topics most tackled recently. The waste-heat-recovery-systems have mostly targeted the energy in the exhaust gas of the engine. Recent researches have pointed out the importance of recovering the energy lost in other forms rather than the exhaust gas, to be recovered alongside the recovery of the exhaust gas energy. In this research, we target to recover the energy in the engine's exhaust gas in one model then to recover the energy in both the engine's exhaust gas and the scavenge air together in another model. The design of the cycle configuration has targeted both the economical side as to design a cycle that is cost-effective to be implemented with no extra cost or complexities, and the thermodynamic side where the design targets to recover the maximum amount of energy possible. The two models were compared then tested the better model at different operating pressures and degrees of superheat.

Key words: Marine diesel engines, waste heat recovery systems, organic Rankine cycle, scavenge air.

Corresponding Author:Fady G. Z. Tawadros

\section{INTRODUCTION}

The usage of Waste Heat Recovery Systems (WHRS) has been one of the most important topics in modern research, as it aims to make use of the energy that humans, for decades, used to drain without any usage. These systems not only aim to recover that once wasted energy and turn it into useful work (energy benefit), but it also achieves alongside this target reduction in amounts of fuel consumed (economic benefit), which accordingly means reduction in amounts of harmful gases (most importantly $\mathrm{CO}_{2}$ ) emitted to the atmosphere (environmental benefit). 
This principle has been applied heavily on marine diesel engines or HDDE (Heavy Duty Diesel Engines) as these engines emit exhaust gases at relatively high temperatures and relatively high flow rates, i.e. emit enormous amounts of energy in their exhaust gases, accordingly this type of engines has become the focus for research aiming to achieve the benefits discussed previously. Besides the already known for decades concept of "Exhaust Gas Boilers" which use the engine exhaust gas for generating steam for mainly heating purposes, most of the previous research focused on using this steam to operate a relatively small Rankine cycle to obtain output net power, that can be later used to generate electricity or for any other purpose. Research has gone from proposing different configurations for the Rankine cycle (like adding feed water heater or using dual pressure cycles) to varying theworking fluid itself, using steam or using organic fluids as the working fluid for the Rankine cycle, i.e. Organic Rankine Cycle (ORC).

While the usage of the engine's exhaust gases to operate the Waste Heat Recovery System (WHRS) used to provide the heat addition for the ORC contributes good energy savings, the introduction of the engine's scavenge air to be cooled (extract its heat energy) into the WHRS, rather than in the charge air cooler normally used, has also contributed much better results and allowed for enormous energy and fuel savings.

Organic fluids themselves have a wide range of variation into their very own structure and chemical composition, leading to a wide range of variation in their critical pressures and temperatures and thermal capacities, therefore selection of the optimum organic fluid for a specific application depends mainly on results obtained from previous testing (previous literature)[1]for a similar application or on conducting several tests for different organic fluids on the very specific application being investigated.

Other parameters involved into the selection of the optimum organic fluid also include its environmental sustainability, ozone depletion potential (ODP) (comparison with the effect of R11), global warming potential (GWP) (comparison with the effect of $\mathrm{CO}_{2}$ ), safety (being non-flammable, non-toxic and non-corrosive) andits thermal stability[2].

For the selection of the organic fluid, to be used as the working fluid for the WHRS ORC for the current research topic, R245fa was selected as it was recommended by multiple previous literature[3], and as it provided the best results for the current system being investigated.

$\mathrm{R} 245 \mathrm{fa}$ is considered to be a benchmark refrigerant, with nearly zero ODP, being nonflammable and of low toxicity while having high degree of thermal and hydrolytic stability[4], besides being within the recommended range of critical point properties suitable for the system investigated[1]. All the former properties lead to R245fa being selected to be the system's working fluid.

As of the progress of research in this topic, in 2007, Tien et al. [5]made an iterative method to implement a WHRS onboard a ship where the exhaust gas is used to produce steam for electricity generation. Also Butcher and Reddy [6]introduced a second-law performance analysis of a WHRS for the same purpose. Then Ma et al. [7]introduced a WHRS working with a container ship diesel engine exhaust gas while analyzing the operation characteristics of the diesel engine. Wei et al. [8]studied the performance of an ORC utilizing the waste heat available from the engine's exhaust gas as the heat source. Also, Etemoglu[9]studied a WHRS unit operating on an ORC for the purpose of generating heat and power. Uusitalo et al. [10]suggested the usage of the charge air as a heat source for the WHRS discussed. Yang [11]suggested to use the exhaust gas, the scavenge air cooling water and the cylinder cooling water as heat sources. Later Yang and Yeh[12]introduced an optimization study based on the thermodynamic and economic performance of an ORC WHRS using the heat available in the exhaust gas of a marine diesel engine.Kyriakidis et al. [13]investigated the same topic with multistage system and using exhaust gas recirculation. 


\section{SYSTEM DESCRIPTION AND MODELLING}

The Marine Diesel Engine used is "Wartsila 6RT-flex58T-E". This is a two-stroke-dieselengine, with constant pressure turbocharging, providing $12457 \mathrm{~kW}$ (16728 HP) at engine maximum continuous service loading. Table(1) shows the operational characteristics of the engine at themaximum continuous service load determined from practical workshop measurements.

Table1. The operational characteristics of the engine at themaximum continuous service load.

\begin{tabular}{|c|c|c|c|}
\hline & Parameter & Value & Unit \\
\hline \multirow{2}{*}{ Scavenge Air } & Mass flow rate & 28.2 & $\mathrm{~kg} / \mathrm{s}$ \\
\cline { 2 - 4 } & Temperature & 213 & ${ }^{\circ} \mathrm{C}$ \\
\hline \multirow{2}{*}{ Exhaust Gas } & Mass flow rate & 28.8 & $\mathrm{~kg} / \mathrm{s}$ \\
\cline { 2 - 4 } & Temperature & 251 & ${ }^{\circ} \mathrm{C}$ \\
\hline
\end{tabular}

A computer model of the system was prepared to simulate the engine and the WHRS being studied, first only the energy in the exhaust gas was recovered (Model 1) then the energy in both the exhaust gas and the scavenge air was recovered (Model 2).

In Model 1, the energy in the exhaust gases was recovered till the temperature of the gases reached a minimum of $150^{\circ} \mathrm{C}$ to prevent formation of sulfuric acid[14], exhaust gases played the role of the heat source for the super heater, the evaporator and the economizer (feed heater) of the waste heat recovery system as indicated in figure(1).

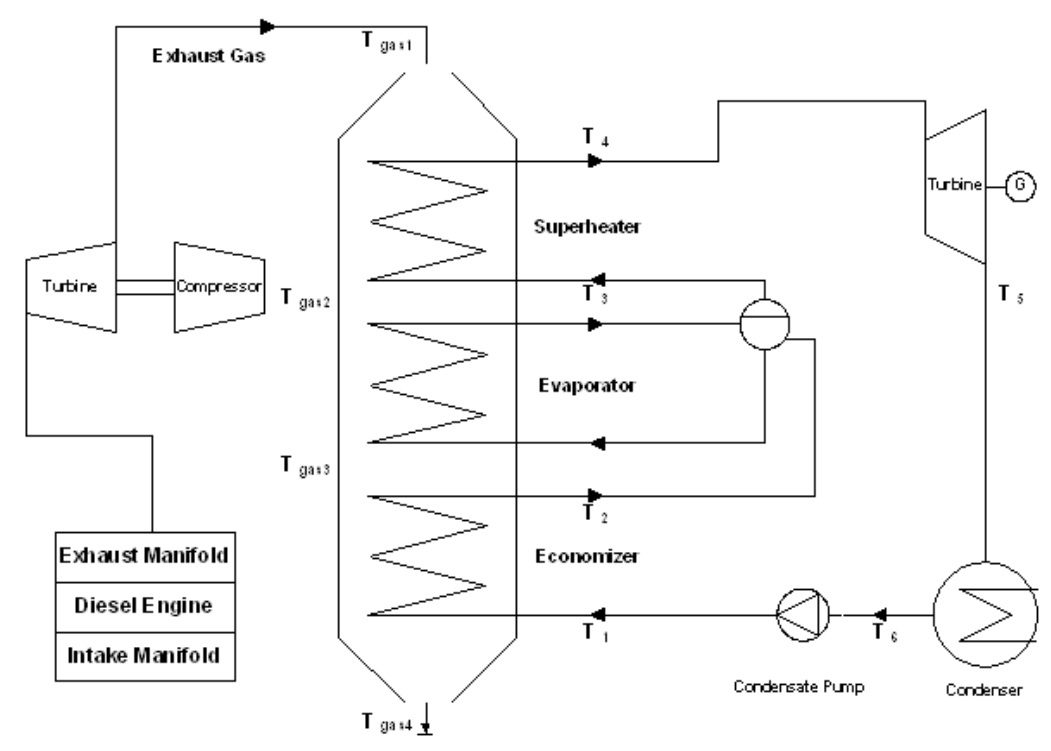

Fig 1: Layout of Model 1

In Model 2, energy in the exhaust gases was recovered till the temperature of the gases reached a minimum of $150^{\circ} \mathrm{C}$, as in model 1 , performing the role of the super heater and the gas evaporator, while the energy in the scavenge was also recovered till the temperature of the air reached a minimum of $55^{\circ} \mathrm{C}$, energy from the scavenge air was used to operate an auxiliary air evaporator, working in-parallel with the already existing gas evaporator, the energy remaining in both the exhaust gases and the scavenge air is used for the economizer role (feed heater) as two feed heaters working in parallel. Model layout is indicated in figure(2). 


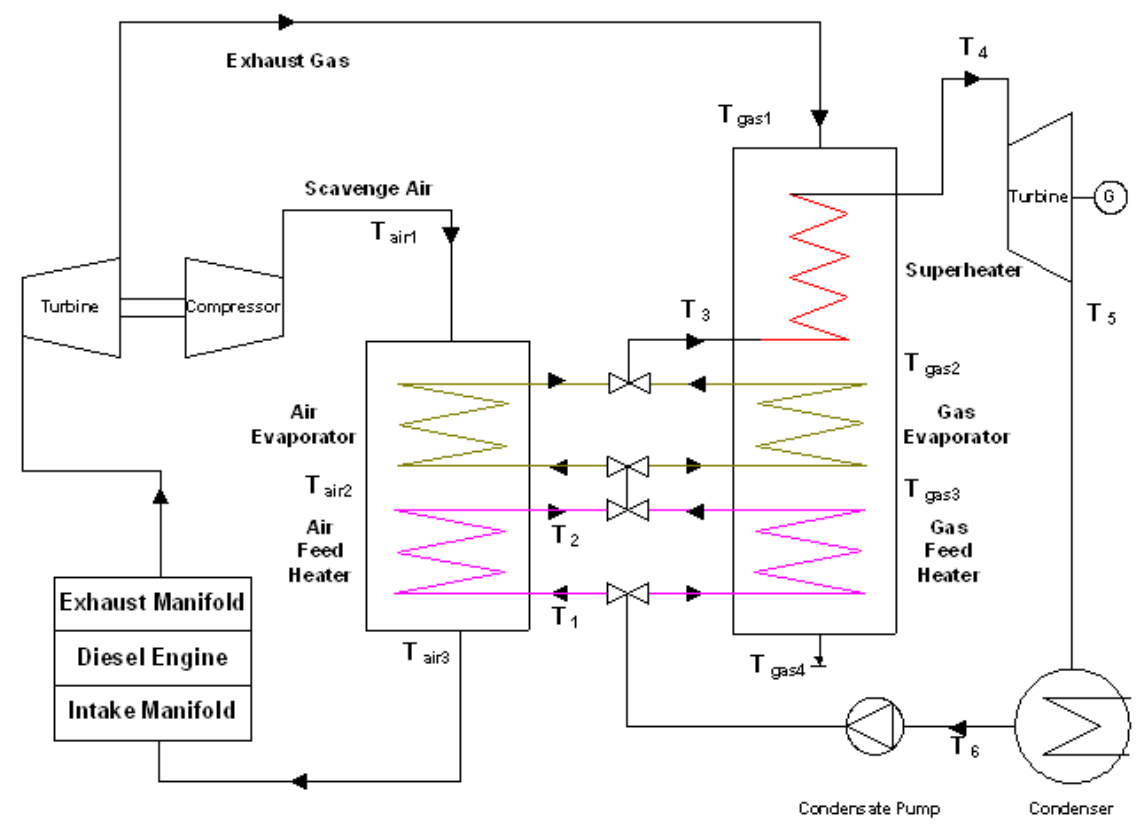

Fig 2: Layout of Model 2

\section{SOLUTION PROCEDURE}

The computer model built was fed with the following set of equations governing the system:

Superheater balance:

$$
\dot{m}_{\text {gas }} * c_{p_{\text {gas }}}\left(t_{\text {gas }_{1}}-t_{\text {gas }_{2}}\right)=\dot{m}_{\text {Ref }}\left(h_{4}-h_{3}\right)
$$

Air Evaporator balance:

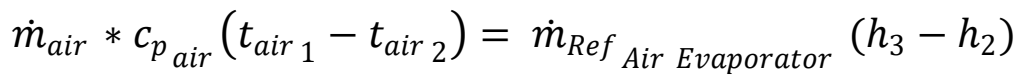

Gas Evaporator balance:

$$
\dot{m}_{\text {gas }} * c_{p_{\text {gas }}}\left(t_{\text {gas }_{2}}-t_{\text {gas }_{3}}\right)=\dot{m}_{\text {Ref }} \text { Gas Evaporator }\left(h_{3}-h_{2}\right)
$$

Air Economizer balance:

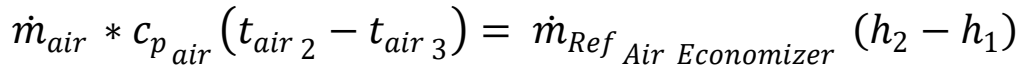

Gas Economizer balance:

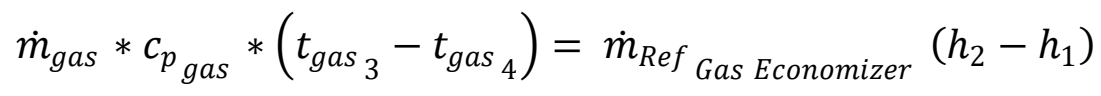

Model 1 can be solved using the same set of equations but substituting for $\left(\dot{m}_{\text {air }}=0\right)$.

\section{RESULTS AND DISCUSSION}

Model 1, the one exploiting only the energy of the exhaust gases, resulted in the WHRS output power to reach $581.3 \mathrm{~kW}$.

In model 2, after making use of the energy in the scavenge air as well, the WHRS reached a power output of $1395 \mathrm{~kW}$, resulting in an increase of $139.98 \%$ of power over model 1. 
As model 2 is the better model to be implemented, a study of the variation the ORC WHRS cycle was conducted to check for the effect of varying the cycle operating pressure on the cycle resulting output power (Figure (3)) and cycle working fluid mass flow rate (Figure (4)).

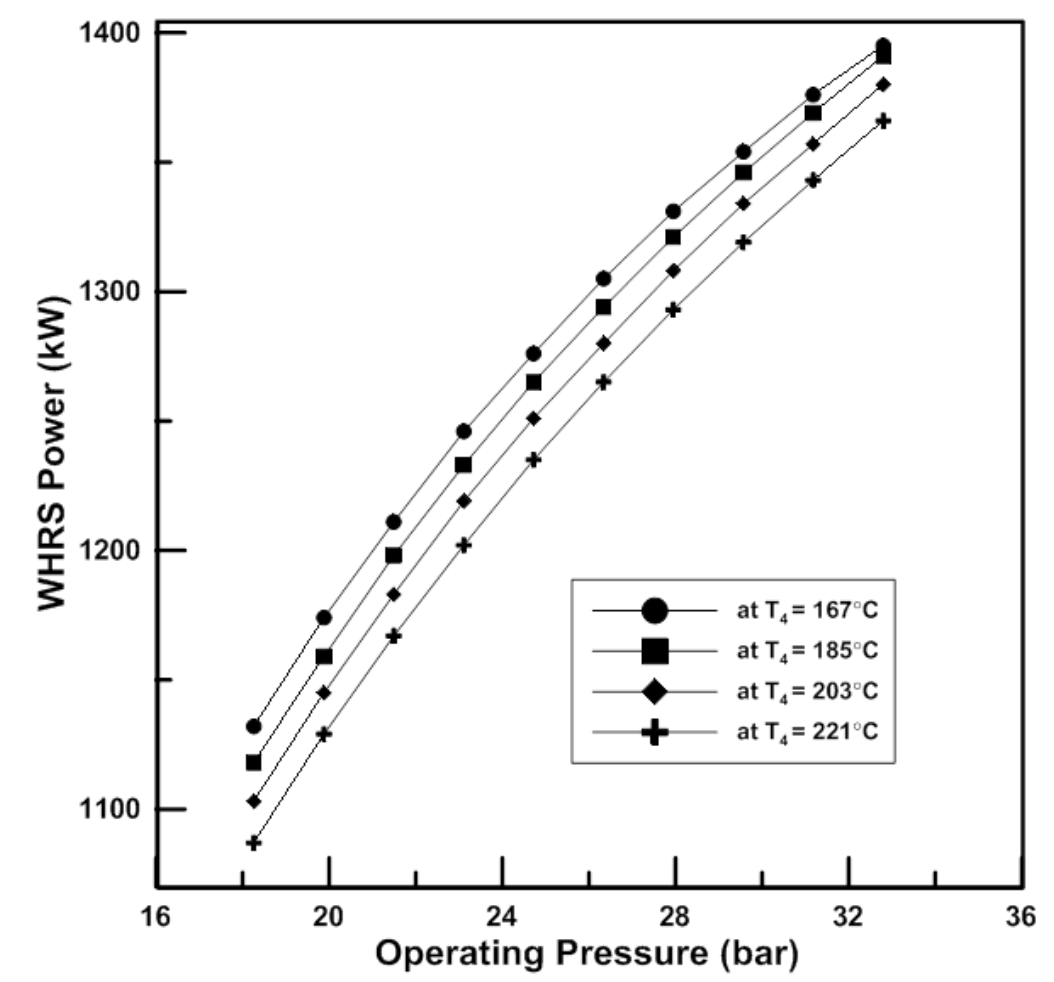

Fig 3: Effect of varying the cycle operating pressure on the cycle resulting output power

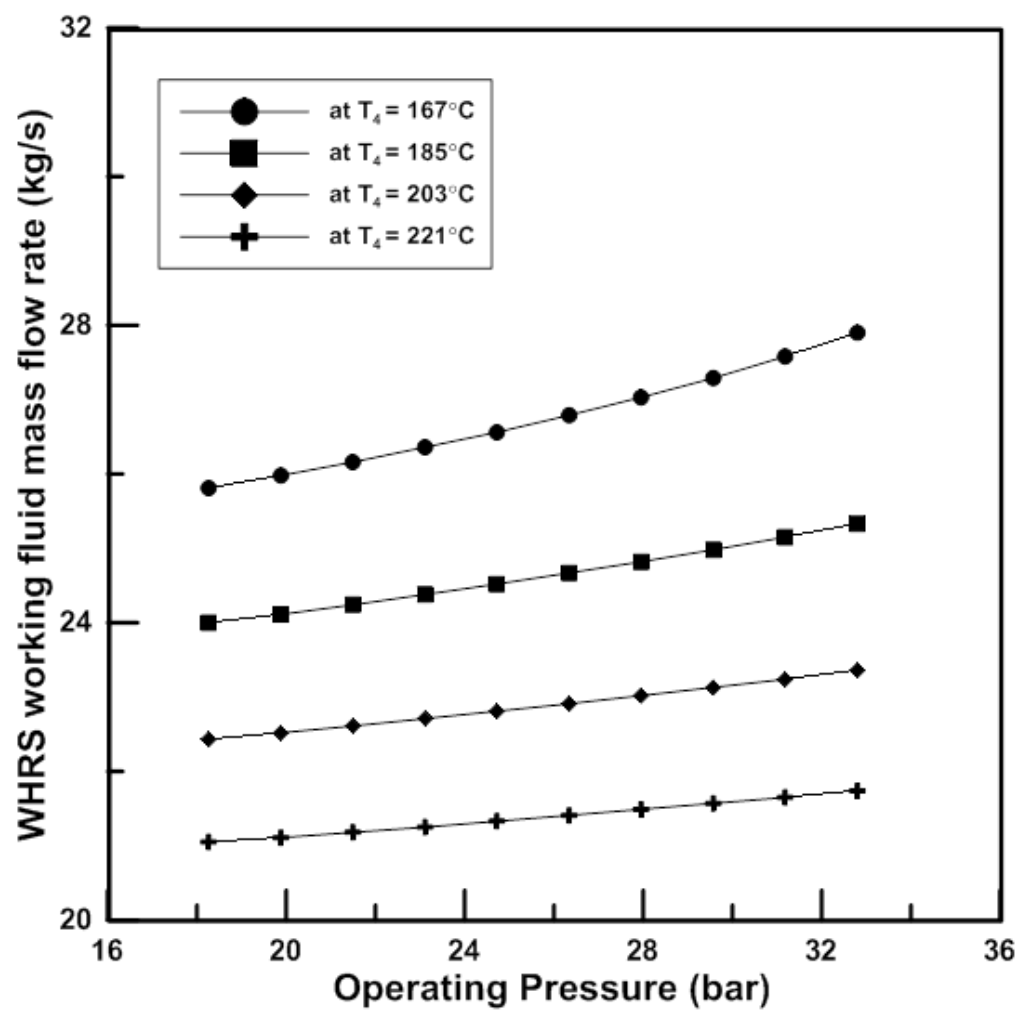

Fig 4: Effect of varying the cycle operating pressure on the cycle working fluid mass flow rate 


\section{CONCLUSION}

Cycle configuration is a critical issue to consider while implementing WHR techniques for large diesel engines. Also using scavenge air cooling alongside the engine's exhaust gas has resulted in an increase of $139.98 \%$ of power over the model using only the exhaust gas.

\section{REFERENCES}

[1] Xu, H., Gao, N., and Zhu, T., 2016, "Investigation on the fluid selection and evaporation parametric optimization for sub- and supercritical organic Rankine cycle," Energy, 96, pp. 59-68.

[2] Darvish, K., Ehyaei, M., Atabi, F., and Rosen, M., 2015, "Selection of Optimum Working Fluid for Organic Rankine Cycles by Exergy and Exergy-Economic Analyses," Sustainability, 7(11), pp. 15362-15383.

[3] Chintala, V., Kumar, S., and Pandey, J. K., 2018, "A technical review on waste heat recovery from compression ignition engines using organic Rankine cycle," Renewable and Sustainable Energy Reviews, 81, pp. 493-509.

[4] Honeywell International Inc. , 2018, "Genetron® 245fa (R-245fa)," https://www.honeywell-refrigerants.com/europe/product/genetron-245fa/.

[5] Tien, W.-K., Yeh, R.-H., and Hong, J.-M., 2007, "Theoretical analysis of cogeneration system for ships," Energy Conversion and Management, 48(7), pp. 1965-1974.

[6] Butcher, C. J., and Reddy, B. V., 2007, "Second law analysis of a waste heat recovery based power generation system," International Journal of Heat and Mass Transfer, 50(11-12), pp. 2355-2363.

[7] Ma, Z., Yang, D., and Guo, Q., 2012, "Conceptual Design and Performance Analysis of an Exhaust Gas Waste Heat Recovery System for a 10000TEU Container Ship.," Polish Maritime Research, 19, pp. 31-38.

[8] Wei, D., Lu, X., Lu, Z., and Gu, J., 2007, "Performance analysis and optimization of organic Rankine cycle (ORC) for waste heat recovery," Energy Conversion and Management, 48(4), pp. 1113-1119.

[9] Etemoglu, A. B., 2013, "Thermodynamic investigation of low-temperature industrial waste-heat recovery in combined heat and power generation systems," International Communications in Heat and Mass Transfer, 42, pp. 82-88.

[10] Uusitalo, A., Honkatukia, J., Turunen-Saaresti, T., and Larjola, J., 2014, "A thermodynamic analysis of waste heat recovery from reciprocating engine power plants by means of Organic Rankine Cycles," Applied Thermal Engineering, 70(1), pp. 33-41.

[11] Yang, M.-H., 2015, "Thermal and economic analyses of a compact waste heat recovering system for the marine diesel engine using transcritical Rankine cycle," Energy Conversion and Management, 106, pp. 1082-1096.

[12] Yang, M.-H., and Yeh, R.-H., 2015, "Thermodynamic and economic performances optimization of an organic Rankine cycle system utilizing exhaust gas of a large marine diesel engine," Applied Energy, 149, pp. 1-12.

[13] Kyriakidis, F., Sørensen, K., Singh, S., and Condra, T., 2017, "Modeling and optimization of integrated exhaust gas recirculation and multi-stage waste heat recovery in marine engines," Energy Conversion and Management, 151, pp. 286-295.

[14] Grljušić, M., Medica, V., and Račić, N., 2014, "Thermodynamic Analysis of a Ship Power Plant Operating with Waste Heat Recovery through Combined Heat and Power Production.," Energies, 7, pp. 7368-7394. 